\title{
Identification of effective properties of the railway substructure in the low-frequency range using a heavy oscillating unit on the track
}

Received: 11 May 2008 / Accepted: 11 July 2009 / Published online: 12 August 2009

(C) The Author(s) 2009. This article is published with open access at Springerlink.com

\begin{abstract}
As the demand for predictions of train-induced vibrations is increasing, it is essential that adequate parameters of the railway structure are given as input in the predictions. Gathering this information can be quite time-consuming and costly, especially when predictions are required for the low-frequency emission. This article presents a procedure for deriving the effective properties of the foundation under the sleepers of a railway track from measurements taken with a heavy oscillating unit on the track. The unit consists of two masses inside a modified freight car that exert a dynamic force in the range $3-30 \mathrm{~Hz}$ on one of the two axles. The ratio of force applied on the axle over the resulting response measured with an accelerometer is studied. The foundation of the sleepers is modelled using a frequency-dependent complex-valued dynamic stiffness.
\end{abstract}

Keywords Embankment $\cdot$ Flexibility $\cdot$ Railway $\cdot$ Stiffness $\cdot$ Track $\cdot$ Train

\section{Introduction}

Higher magnitudes of train-induced vibrations on railway embankments increase maintenance costs. Vibrations propagating into the track vicinity also disturb people nearby, and can cause sensitive equipment to malfunction. In extreme cases, excessive vibrations can also cause damage to buildings.

As railway lines are used with increasing frequency, there is growing demand for predicting train-induced ground vibrations on the embankment and in the track vicinity. A particularly demanding task is making predictions over a long railway line when knowledge about the geotechnical conditions is limited.

Train-induced track and ground vibrations are modelled in various ways [1,2,4-24]. These models are used for different purposes, and to suit a variety of demands, therefore, there are different degrees of precision, as well as types of input. Regardless of the model used, it is vital that adequate parameters are given as input. Gathering this information can be both time-consuming and costly.

This article presents a method of how to quickly gain knowledge of the effective properties of the railway substructure along railway lines of significant length with minimum disturbance to the normal traffic. The method focuses on the parameter identification in the low-frequency range of 3-27 Hz, which normally requires heavy and relatively immobile equipment. The dominating frequencies that a train excites the embankment

C. With $(\bowtie) \cdot$ A. Bodare

Department of Civil and Architectural Engineering, Royal Institute of Technology (KTH),

Brinellvägen 34, 10044 Stockholm, Sweden

E-mail: christoffer.with@byv.kth.se

Tel.: +4670 7765405

Fax: +4687907928

\section{A. V. Metrikine}

Faculty of Civil Engineering and Geoscience, Delft University of Technology (TUDelft),

Stevinweg 1, 2628 CN Delft, The Netherlands 
with are generally found to be below $30 \mathrm{~Hz}$ if the investigation is carried out with geophones. The method is facilitated by a modified freight car called the rolling stiffness measurement vehicle (RSMV). In this car, two heavy vibrators are installed which can exert dynamic force on one of the two axles. The installed equipment allows the axle acceleration and the vertical force on the axle to be measured simultaneously. This paper proposes a simple technique for identifying the frequency-dependent dynamic stiffness of the railway substructure from the force and acceleration measurements. This technique is based on an assumption that the wave-number dependence of the dynamic stiffness [3] can be neglected in the low-frequency range.

The technique presented in this paper makes use of the measurements performed on a stationary car, not moving along the railway track.

\section{Theory}

This section describes a model that can be used to evaluate the measured response of the track caused by the oscillating masses inside a stationary car (RSMV). The model accounts only for the vertical motion of the car, the rails and the sleepers. A sketch of the model is shown in Fig. 1. The rails are modelled as a BernoulliEuler beam (BE) supported by a continuous visco-elastic foundation that represents the pads. The pads rest on the sleepers that are modelled as a continuously distributed mass, i.e. a beam without the bending stiffness. The sleepers and the pads can be considered to be continuously distributed as the low-frequency dynamics of the track is investigated in this paper. In this frequency range, the wavelength of motion of the rails is much larger than the sleeper spacing and the discrete character of the rail support system may be smeared. The sleepers are supported by the ground that is schematised as a one-dimensional foundation with a complex-valued frequency-dependent stiffness. Only one half of the car is taken into account and modelled, as shown in Fig. 1. The half-car is suspended on the axle through a force transducer that is modelled as a spring. The system is excited by harmonically oscillating masses inside the car.

Below, the equations are given that describe small vertical vibrations of the system in the frequency domain. It is assumed that the time-frequency relation is characterised by

$$
w(x, t)=w(x) \mathrm{e}^{-\mathrm{i} \omega t} .
$$

The differential equation that governs vertical vibrations of the rails (the beam) is given as

$$
\begin{gathered}
E I \frac{d^{4} w_{\text {rails }}(x)}{d x^{4}}-\rho A \omega^{2} w_{\text {rails }}(x)+\chi_{\text {pads }}\left(w_{\text {rails }}(x)-w_{\text {sleepers }}(x)\right)=0, \quad|x|>0 \\
\chi_{\text {pads }}=\kappa_{\text {pads }}-\mathrm{i} \omega \delta_{\text {pads }}
\end{gathered}
$$

where $E I$ is the bending stiffness of the two rails, $w_{\text {rails }}$ is the vertical displacement of the rails, and $\rho$ and $A$ are the mass density and the cross-sectional area of the rails. The stiffness of the pads $\chi_{\text {pads }}$ is characterised

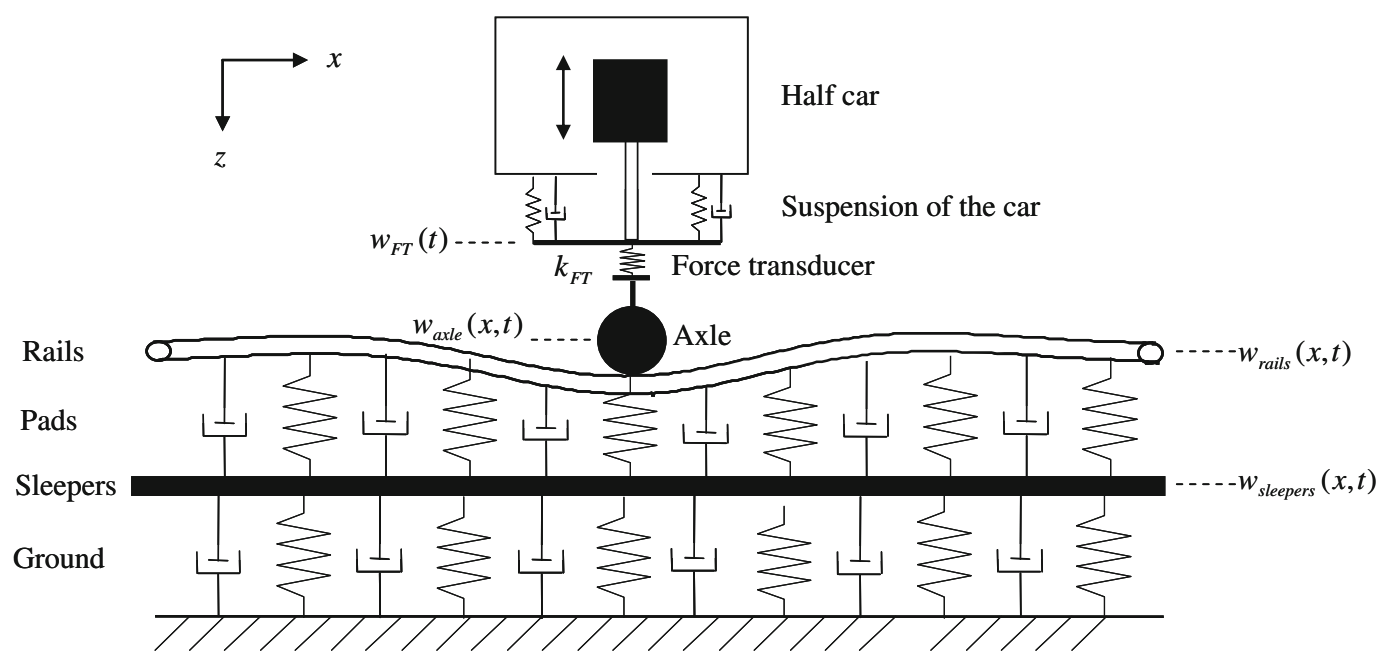

Fig. 1 Sketch of the model used to describe the system. Force transducer (FT). Axle includes the masses of the two wheels 
by the distributed constant stiffness $\kappa_{\text {pads }}$ and the distributed damping constant $\delta_{\text {pads }} . w_{\text {sleepers }}$ is the vertical displacement of the sleepers. $\omega$ is the angular frequency of oscillation of the masses in the car.

The motion of the sleepers is governed for all $x$ by

$$
\begin{gathered}
-m_{\text {sleepers }} \omega^{2} w_{\text {sleepers }}(x)+\chi_{\text {pads }}\left(w_{\text {sleepers }}(x)-w_{\text {rails }}(x)\right)+\chi_{\text {ground }}(\omega) w_{\text {sleepers }}(x)=0 \\
\chi_{\text {ground }}(\omega)=\chi_{\text {ground }}^{\operatorname{Re}}(\omega)-\mathrm{i} \chi_{\text {ground }}(\omega)
\end{gathered}
$$

in which $m_{\text {sleepers }}$ is the mass of the sleepers per unit length and $\chi_{\text {ground }}(\omega)$ is the complex-valued, frequencydependent stiffness of the ground. The motion of the axle assumed to be in contact with the rail is governed by the following equation:

$$
\begin{gathered}
-m_{\text {axle }} \omega^{2} w_{\text {axle }}(x)+k_{\mathrm{FT}}\left(w_{\text {axle }}-w_{\mathrm{FT}}\right)-E I\left(\frac{d^{3} w_{\text {rails }}}{d x^{3}}(x=+0)-\frac{d^{3} w_{\text {rails }}}{d x^{3}}(x=-0)\right)=0 \\
w_{\text {axle }}=w_{\text {rails }}(x=0)
\end{gathered}
$$

where $w_{\text {axle }}$ and $w_{\mathrm{FT}}$ are the displacements of the axle and force transducer $(\mathrm{FT})$, respectively, and $k_{\mathrm{FT}}$ is the stiffness of the force transducer.

The motion of the car is governed by the following equation:

$$
\begin{gathered}
-m_{\text {car }} \omega^{2} w_{\text {car }}(x)+K_{\text {suspension }}\left(w_{\text {car }}-w_{\mathrm{FT}}\right)=0 \\
K_{\text {suspension }}=k_{\text {suspension }}-\mathrm{i} \omega c_{\text {suspension }}
\end{gathered}
$$

where the stiffness of the suspension $K_{\text {suspension }}(\omega)$ is characterised by the stiffness $k_{\text {suspension }}$ and the damping

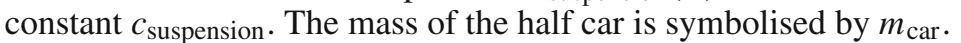

At the contact point between the beam and the axle mass, the following three boundary conditions must be satisfied:

$$
\begin{gathered}
w_{\text {rails }}(x=+0)=w_{\text {rails }}(x=-0) \\
\frac{d w_{\text {rails }}}{d x}(x=+0)=\frac{d w_{\text {rails }}}{d x}(x=-0) \\
\frac{d^{2} w_{\text {rails }}}{d x^{2}}(x=+0)=\frac{d^{2} w_{\text {rails }}}{d x^{2}}(x=-0)
\end{gathered}
$$

The solution of Eqs. (2) and (4) that is valid for $x>0$ and satisfies the boundary condition at $x \rightarrow \infty$ (zero displacement at the infinity) can be written as

$$
\begin{gathered}
w_{\text {rails }}^{+}(x)=\sum_{j=1}^{2} A_{j} e^{k_{j} x}, \quad w_{\text {rails }}^{+}(x)=w_{\text {rails }} \quad(x \geq 0) \\
w_{\text {sleepers }}^{+}(x)=\sum_{j=1}^{2} B_{j} e^{k_{j} x}, \quad w_{\text {sleepers }}^{+}(x)=w_{\text {sleepers }} \quad(x \geq 0)
\end{gathered}
$$

assuming that the real parts of $k_{1}$ and $k_{2}$ are negative.

Inserting Eqs. (13) and (14) in Eqs. (2) and (4), the following two equations with respect to $A_{j}$ and $B_{j}$ can be obtained:

$$
\begin{gathered}
A_{j}\left(E I k_{j}^{4}-\rho A \omega^{2}+\chi_{\text {pads }}\right)-B_{j} \chi_{\text {pads }}=0 \\
-A_{j} \chi_{\text {pads }}+B_{j}\left(-m_{\text {sleepers }} \omega^{2}+\chi_{\text {pads }}+\chi_{\text {ground }}(\omega)\right)=0
\end{gathered}
$$

Setting the determinant of the $2 \times 2$ coefficient matrix defined by Eqs. (15) and (16) to zero, the following expression for $k_{j}^{4}$ can be found:

$$
k_{j}^{4}=\frac{\rho A \omega^{4} m_{\text {sleepers }}-\rho A \omega^{2}\left(\chi_{\text {pads }}(\omega)+\chi_{\text {ground }}(\omega)\right)-m_{\text {sleepers }} \omega^{2} \chi_{\text {pads }}(\omega)+\chi_{\text {pads }}(\omega) \chi_{\text {ground }}(\omega)}{E I\left(-m_{\text {sleepers }} \omega^{2}+\chi_{\text {pads }}(\omega)+\chi_{\text {ground }}(\omega)\right)}
$$


Introducing

$$
k_{0}=\sqrt[4]{k_{j}^{4}}, \quad \operatorname{Re}\left(k_{o}\right)>0, \quad \operatorname{Im}\left(k_{o}\right)>0
$$

which belongs to the first quadrant of the complex $k$-plane, allows the following two roots of Eq. (17) to be defined that have a negative real part:

$$
\begin{aligned}
& k_{1}=-k_{0} \\
& k_{2}=\mathrm{i} k_{0}
\end{aligned}
$$

Using the symmetry of the system with respect to $x=0$, Eq. (6) can be rewritten as

$$
\begin{aligned}
2 E I \frac{d^{3} w_{\text {rails }}^{+}}{d x^{3}}(x=0) & =-m_{\text {axle }} \omega^{2} w_{\text {axle }}+k_{\mathrm{FT}}\left(w_{\text {axle }}-w_{\mathrm{FT}}\right) \\
w_{\text {axle }} & =w_{\text {rails }}^{+}(x=0)
\end{aligned}
$$

Also due to the symmetry, Eq. (11) can be reduced to $d w_{\text {rails }}^{+} / d x(x=0)=0$. Substituting Eq. (13) into this equation and into Eq. (21), it can be found that

$$
2 E I \frac{d^{3} w_{\text {rails }}^{+}}{d x^{3}}(x=0)=-w_{\text {rails }}^{+}(x=0) \chi_{\text {rails }}(\omega)
$$

where

$$
\chi_{\text {rails }}(\omega)=-2 E I k_{1} k_{2}\left(k_{1}+k_{2}\right)
$$

Consequently, taking into account Eq. (22), Eq. (21) can be rewritten as

$$
-m_{\text {axle }} \omega^{2} w_{\text {axle }}+k_{\mathrm{FT}}\left(w_{\text {axle }}-w_{\mathrm{FT}}\right)+\chi_{\text {rails }}(\omega) w_{\text {axle }}=0
$$

To use Eq. (26) for identification of the ground dynamic stiffness, it is customary to introduce the dynamic stiffness $\chi_{\text {measured }}(\omega)$ measured at the axle. The latter dynamic stiffness is defined as the ratio of the force $F_{\mathrm{FT}}$ measured by the force transducer and the displacement of the axle $w_{\text {axle }}$ (both in the frequency domain). Taking into account that the force $F_{\mathrm{FT}}$ and the vertical acceleration $a_{\text {axle }}$ measured on the axle are given as

$$
\begin{gathered}
F_{\mathrm{FT}}=k_{\mathrm{FT}}\left(w_{\mathrm{FT}}-w_{\mathrm{axle}}\right) \\
a_{\mathrm{axle}}=-\omega^{2} w_{\mathrm{axle}}
\end{gathered}
$$

The measured dynamic stiffness can be calculated from the measured quantities as

$$
\chi_{\text {measured }}(\omega)=-\omega^{2} \frac{F_{\mathrm{FT}}}{a_{\text {axle }}}
$$

Using Eqs. (26)-(28), Eq. (25) can be rewritten as

$$
-m_{\mathrm{axle}} \omega^{2}+\omega^{2} \frac{F_{\mathrm{FT}}}{a_{\mathrm{axle}}}+\chi_{\text {rails }}(\omega)=0
$$

Thus, to identify the ground stiffness $\chi_{\text {ground }}(\omega)$, the following function must be minimised at each frequency:

$$
F_{\text {min }}=\left|\omega^{2} \frac{F_{\mathrm{FT}}}{a_{\text {axle }}}-m_{\text {axle }} \omega^{2}+\chi_{\text {rails }}(\omega)\right|
$$

Note that the first term on the right-hand side of Eq. (30) is a measured function of the frequency.

In the evaluation process, which is iterative, the ground stiffness is found. The distributed dynamic stiffness $\chi_{\text {ground }}(\omega)$ of the ground, as follows from evaluation of the measurements performed at the Kumla site, is presented later in the article, following a description of the measurements and the known system parameters. 


\section{Measurements}

The railway line, known as Godsstråket, between Hallsberg-Örebro in the middle of Sweden runs through the small community of Kumla where the field test was conducted.

\subsection{Track}

The bending stiffness and the mass per unit length of the two rails are $E I=12.8 \mathrm{MN} \mathrm{m}^{2}$ and $\rho A=120 \mathrm{~kg} / \mathrm{m}$, respectively. The sleeper spacing $d$ is $0.65 \mathrm{~m}$. With the mass of $M_{\text {sleeper }}=250 \mathrm{~kg}$ for a single concrete sleeper, the distributed mass of the sleepers is $m_{\text {sleepers }}=M_{\text {sleeper }} / d \approx 385 \mathrm{~kg} / \mathrm{m}$. Each sleeper is supported by two pads, each of which has a stiffness $K_{\text {pad }}=80 \mathrm{MN} / \mathrm{m}$ and a damping $D_{\text {pad }}=80 \mathrm{kN} \mathrm{s} / \mathrm{m}$. Correspondingly, the distributed stiffness and the distributed damping of the pads as used in the model are $\kappa_{\text {pads }}=2 K_{\text {pad }} / d \approx 246 \mathrm{MN} / \mathrm{m}^{2}$ and $\delta_{\text {pads }}=2 D_{\text {pad }} / d=43 \mathrm{kN} \mathrm{s} / \mathrm{m}^{2}$.

These properties of the pads have been estimated using [14] and communication with The Swedish Rail Administration (Banverket).

\subsection{Rolling stiffness measurements vehicle (RSMV)}

The RSMV is a modified freight car with two axles, shown in Figs. 1 and 2. The total mass of the RSMV is 29 metric tonnes. The weight of one wheelset (two wheels and one axle) is 1.34 metric tonnes. Two masses, each weighing four tonnes, have been installed over one of the axles. The masses can be forced to oscillate in the range of 3-50 Hz with the help of hydraulic powered pistons at both ends of the axle. The motion of the masses is synchronised. The force is measured under both pistons with force transducers and acceleration with accelerometers next to the transducer.

The RSMV can operate while the car is standing still or being pulled behind an engine $[1,23,24]$. However, in order to evaluate the measurements without having to take the speed of the car and the question of spatial resolution into account, the RSMV was stationary. The frequency interval within which the RSMV could operate was limited to 3-30 Hz. The force applied to the axle and the responding acceleration was measured in time domain with a sampling frequency of $180 \mathrm{~Hz}$ (Fig. 4). The signals were then transformed into the frequency domain (Fig. 5). The signals from the accelerometer were integrated to find the displacement. The real and imaginary values of measured stiffness are presented in Fig. 6. The absolute values of the stiffness and flexibility are presented in Figs. 6 and 7, respectively.

To complete the whole range of 3-50 Hz, the oscillation had to be stopped halfway for adjustment. This procedure would have taken a significant amount of time. The railway line is quite frequently used and there was

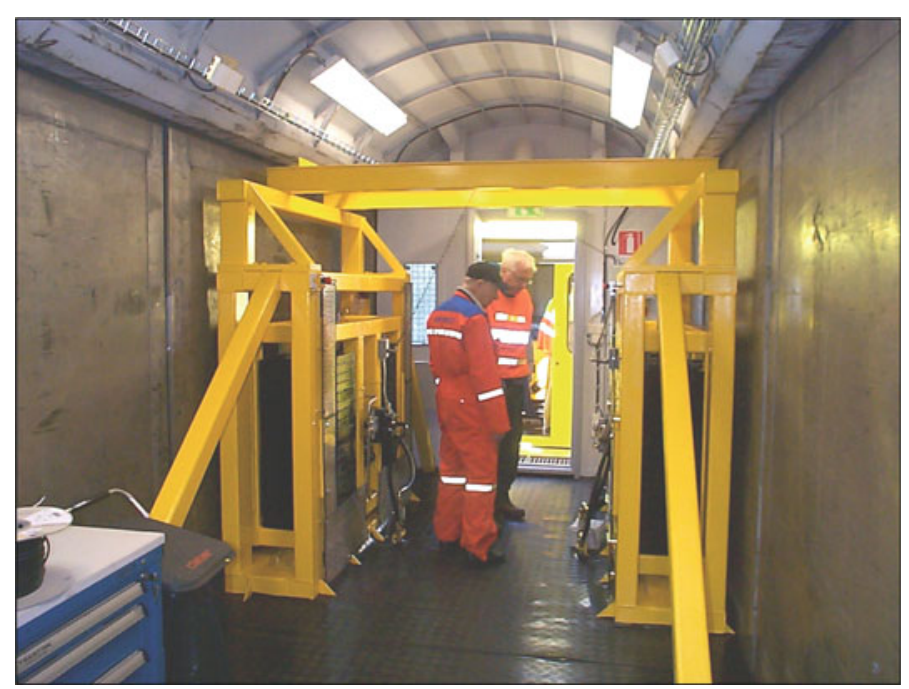

Fig. 2 Inside the RSMV, the weights in the rack above the rear axle are set in motion with hydraulic pistons [24] 


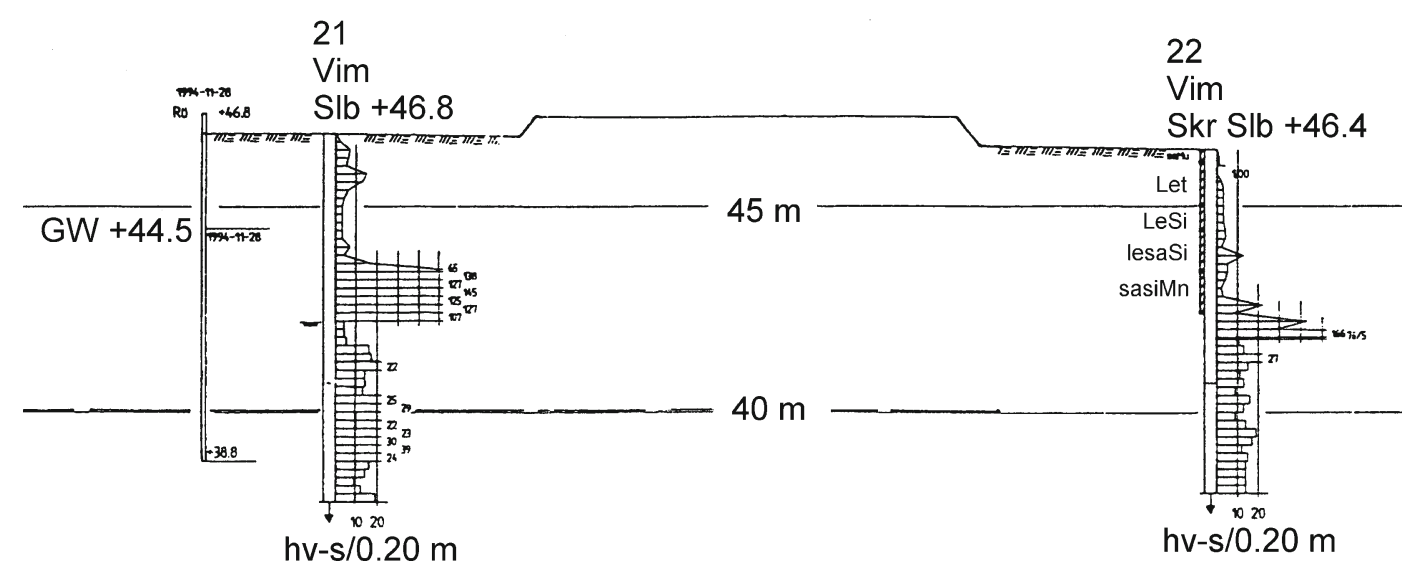

Fig. 3 Site investigation at Kumla. Two different geotechnical in-situ probing tests were conducted to gain information on weight sounding (Vim) and percussion sounding (Slb) [23] + +46.8 gives the elevation compared to the local coordinate system used
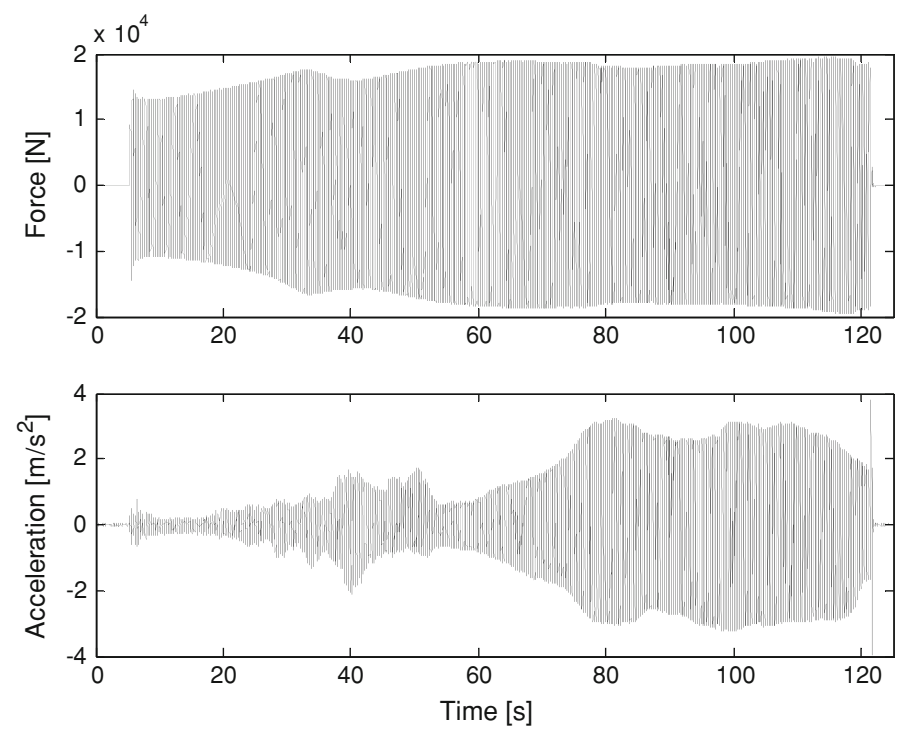

Fig. 4 In time domain measured force (top), acceleration measured on the RSMV axle (bottom)

not sufficient time for this procedure when this measurement was taken. Therefore, the investigated frequency range is limited to $3-30 \mathrm{~Hz}$.

\subsection{Geotechnical site information}

The geotechnical information was not used in the analysis of the site, but it is presented here for the readers' convenience.

The top $0.5 \mathrm{~m}$ is cultivated soil overlying clay with silt/sand and cobbles down to approximately $1.2 \mathrm{~m}$. The proportion of sand and cobble material increases with depth. At about 3-4 m below the surface, the soil is quite firm and has been classified as till. At a depth of about $6 \mathrm{~m}$, larger quantities of cobbles of greater sizes have been found. In records from previous investigations by others, the density seems to be almost constant at $2100 \mathrm{~kg} / \mathrm{m}^{3}$. This value is quite high. The authors had no means to verify this value but could confirm that the soil is rather dense. Measurements, taken 10 years before the RSMV test, found the groundwater surface at $2 \mathrm{~m}$ below the surface $(+44.5)$. The height of the railway embankment was about $1 \mathrm{~m}$. Figure 3 presents data from two bore holes. The shear wave velocity was measured at $190 \mathrm{~m} / \mathrm{s}$ in the ballast and $160 \mathrm{~m} / \mathrm{s}$ in the upper soil surface. 

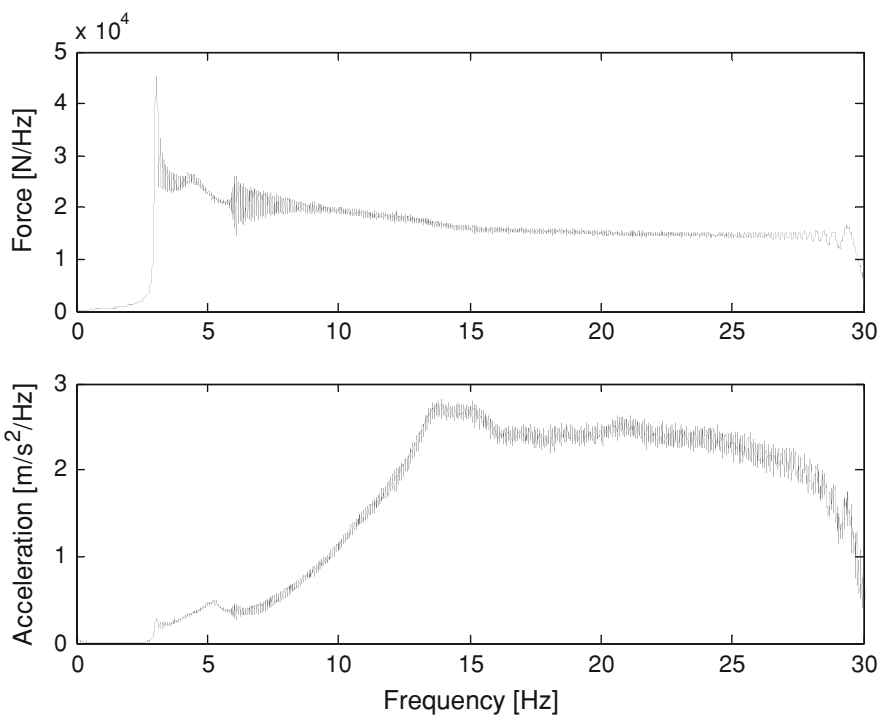

Fig. 5 In frequency domain measured force (top), acceleration measured on the RSMV axle (bottom)

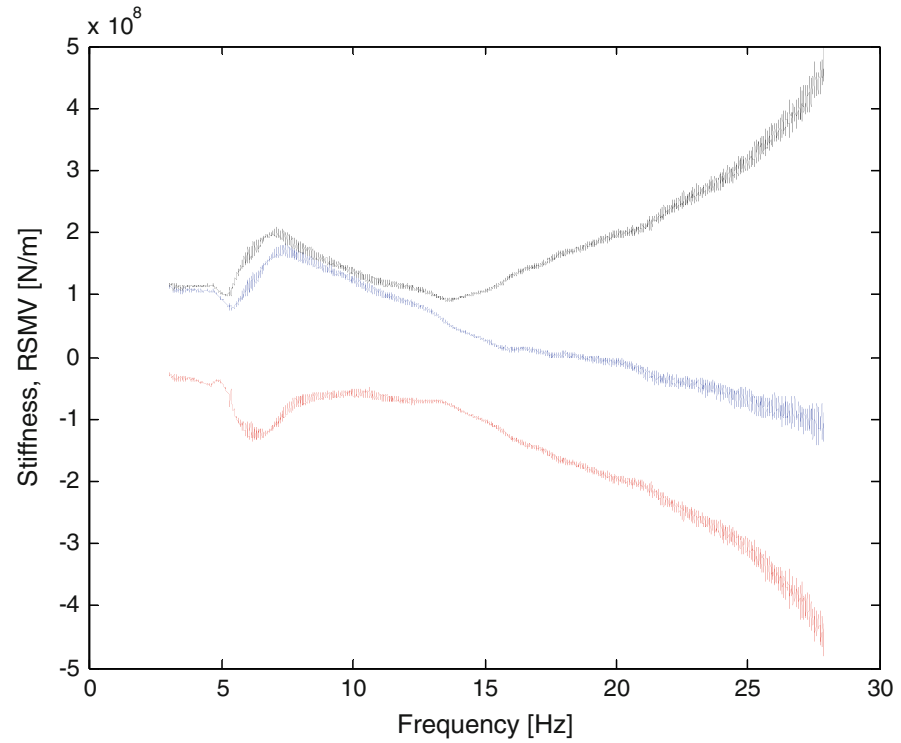

Fig. 6 The absolute value of the stiffness measured on the axle (black), the real part of the stiffness (blue), and the imaginary part (red)

\section{Results}

The signals recorded on the RSMV axle were measured in the time-domain with a sampling frequency of $180 \mathrm{~Hz}$ (Fig. 4). The same signals transformed into the frequency domain, are presented in Fig. 5. All comparisons and calculations made between theory and measurements in order to derive parameters are carried out in the frequency domain.

The RSMV was programmed to give a sweeping sinusoidal force signal from 3 to $30 \mathrm{~Hz}$. Figure 5 shows the magnitudes of the force and acceleration are unstable at the beginning and the end of the interval.

The real and imaginary parts of the stiffness measured on the axle are presented in Fig. 6. The absolute value of the stiffness and the flexibility are presented in Figs. 6 and 7, respectively.

The identified absolute value, the real and the imaginary parts of the dynamic stiffness of the ground $\chi_{\text {ground }}(\omega)$ are presented in Fig. 8. The real part of the dynamic stiffness reflects the elastic and the inertial properties of the railway substructure (everything that is below the sleepers), whereas its imaginary part gives 


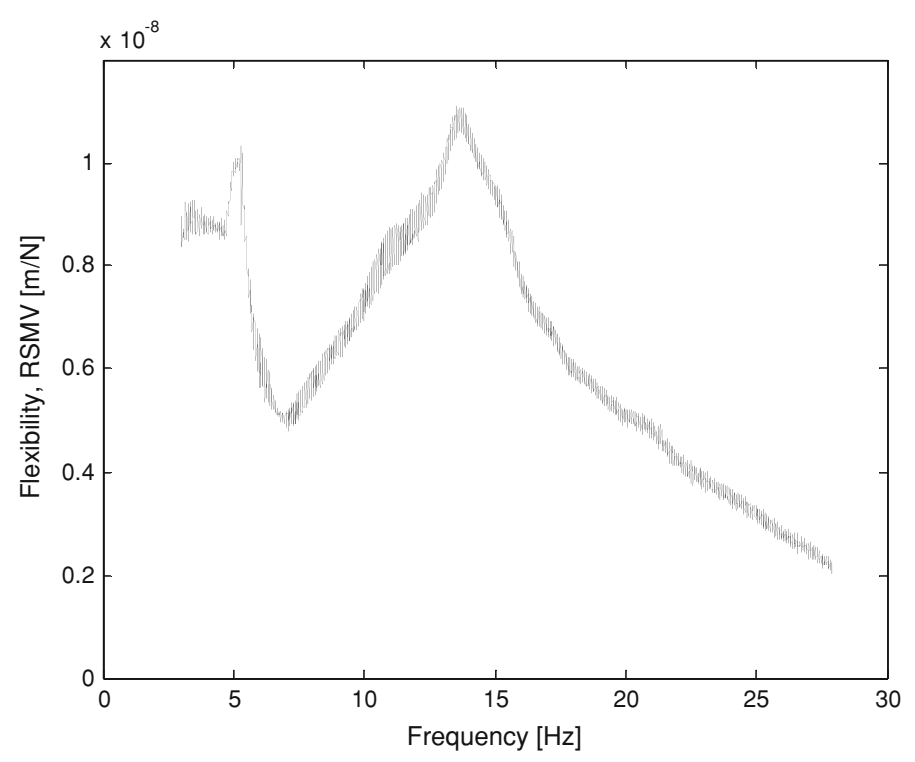

Fig. 7 The absolute value of the flexibility measured on the axle

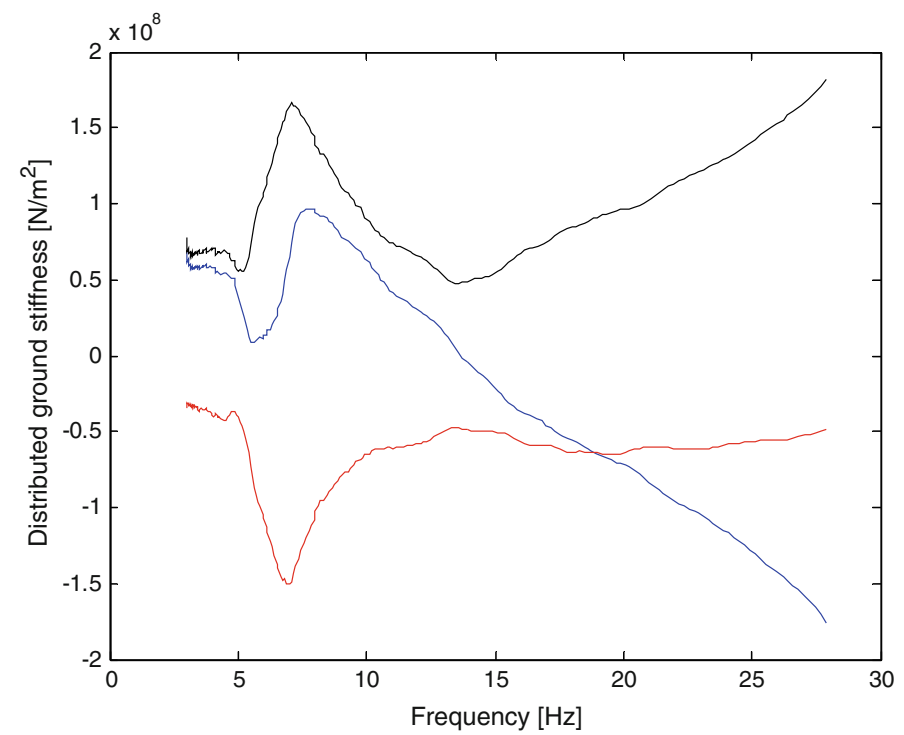

Fig. 8 The absolute value of the distributed ground stiffness (black), the real part (blue), and the imaginary part (red)

the amount of damping. One should note that the imaginary part of $\chi_{\text {ground }}(\omega)$ reflects both the material and the radiation damping mechanisms.

The frequency dependence of the real part of $\chi_{\text {ground }}(\omega)$ shows that the dynamic reaction of the railway substructure changes from elastic to inertial type at about $14 \mathrm{~Hz}$. The imaginary part of $\chi_{\text {ground }}(\omega)$ does not show a pronounced variation except in the $5-9 \mathrm{~Hz}$ range. In the same frequency range, the real part also shows a resonance-type variation.

It was not possible to identify the physical reason for the sharp variation of the dynamic stiffness $\chi_{\text {ground }}(\omega)$ on the basis of the measurements made. It is clear, however, that this variation may correspond either to an eigenfrequency of the car, alternatively to a cut-off frequency, or resonance frequency of the subgrade. This issue will be briefly discussed in the following section. 


\section{Discussion and conclusion}

The main aim of this study has been to investigate the possibility of using an oscillating unit on a railway track to assess the mechanical properties of the track's subgrade in the low-frequency range. To achieve this, a special measuring car (RSMV) has been used which can excite low-frequency oscillation, 3-30 Hz, of the railway structure. The force applied to one axle of the measuring car and the resulting acceleration have been measured simultaneously. The force transducer was installed in such a way that the total vertical force applied on the axle has been measured.

A one-dimensional model of the car-railway system was proposed. The intention was not to introduce any specific three-dimensional model of the subgrade. The model presented only accounts for the vertical vibration of the system and consists of (i) a damped system representing the car, and the oscillating masses it contained, as well as the instrumented axle; (ii) a one-dimensional model for the rail-pad-sleeper system; (iii) a foundation under the sleepers representing the subgrade. This foundation has been assumed to have a frequency-dependent complex stiffness, which has been identified in this article using the measurements taken. It has also been assumed that the stiffness of the foundation is wave-number independent. The latter assumption assumes a weak wave-number dependence in the measured low-frequency band. The correctness of this assumption has not been evaluated in this paper.

The identification procedure carried out in this article has shown that the stiffness of the foundation is a non-monotonic and significantly non-constant function of the frequency. The real part of the ground stiffnessresponsible for the elastic and the inertial properties of the subgrade-has a clear absolute minimum (zero) at about $14 \mathrm{~Hz}$, which gives a minimum in the presentation of the absolute ground stiffness. The imaginary part that reflects the amount of effective damping (including the material and radiation damping mechanisms) has a minimum at about $7 \mathrm{~Hz}$. If the measurements were carried out at a softer ground with a greater proportion of clay versus sand, the magnitude of the ground stiffness would be reduced relative to the present measurements. Furthermore, the resonance frequency/frequencies depending on the sub-grade would be found to have been reduced.

The results of the performed measurements do not explicitly explain the frequency-dependence of the identified stiffness. The reason is that it is unclear whether the resonance-type peaks in the stiffness reflect the dynamic characteristics of the car or those of the subgrade. It is possible that the resonance peaks reflect one of the natural frequencies of the car that has appeared in the measurements due to the vibration transfer between the axles through the subgrade. It could be the resonance frequency of a layer or combination of layers in the soil. The latter is believed to be the case for the resonance at about $14 \mathrm{~Hz}$ seen in Fig. 7.

A new set of measurements is suggested that would include a synchronised acceleration and force measurement on both axles. Identification of the structure and properties of the subgrade, i.e. shear wave velocity and density, is also advised. This would allow conclusions to be drawn regarding the possible influence of the second axle and the soil layers below the embankment. Synchronised measurements on the rail at known intervals would allow investigations of possible influences of wave-number dependence.

Acknowledgments The Swedish Rail Administration (Banverket) is gratefully acknowledged for their contribution to the project and crew of the RSMV. A special thanks to Mr. A. Smekal as representative of Banverket, and Mr. E. Berggren who led the work on the measuring car and provided some property values for the vehicle. The TUDelft grants program is acknowledged for granting the Junior Fellowship for 5 months to C. With. We thank Dr. B. Andréasson and the archive at Banverket Sundbyberg for their contribution on geotechnical site conditions. We would also like to thank Kumla County for allowing us to conduct the measurements on their property, as well as the reviewers for there valuable comments.

Open Access This article is distributed under the terms of the Creative Commons Attribution Noncommercial License which permits any noncommercial use, distribution, and reproduction in any medium, provided the original author(s) and source are credited.

\section{References}

1. Berggren, E.: Dynamic track stiffness measurement-a new tool for condition monitoring of track substructure. Lic. Thesis, Royal Institute of Technology (2005)

2. Bodare, A., Petek, K.: Sub and super seismic train induced ground vibrations-theoretical considerations and test results. In: Proceedings of the 2nd International Symposium on Environmental Vibrations-Prediction, Monitoring, Mitigation and Evaluation, Okayama (2005)

3. Dieterman, H.A., Metrikine, A.: The equivalent stiffness of a half-space interacting with a beam. Critical velocities of a moving load on the beam. Eur. J. Mech. 15, 67-90 (1996) 
4. Hall, L.: Simulations and analyses of train-induced ground vibrations in finite element models. Soil Dyn. Earthquake Eng. 23, 403-413 (2002)

5. Jones, C.J.C., Block, J.R.: Prediction of ground vibration from freight trains. J. Sound Vib. 193, 205-213 (1996)

6. Jones, C.J.C., Sheng, X., Petyt, M.: Simulations of ground vibration from a moving harmonic load on a railway track. J. Sound Vib. 231, 739-751 (2000)

7. Karlström, A., Boström, A.: An analytical model for train-induced ground vibrations from railways. J. Sound Vib. 292, 221$241(2005)$

8. Kaynia, A.M., Madshus, C., Zackrisson, P.: Ground vibrations from high-speed trains: predictions and countermeasures. J. Geotech. Geoenviron. Eng. 126, 531-537 (2000)

9. Krylov, V.V.: Generation of ground vibration boom by high-speed trains. In: Krylov, V.V. (ed.) Noise and Vibration from High-speed Trains, pp. 251-283. Thomas Telford Publishing, London (2001)

10. Lombaert, G., Degrande, G., Kogut, J., Francois, S.: The experimental validation of a numerical model for the prediction of railway induced vibrations. J. Sound Vib. 297, 512-535 (2006)

11. Madshus, C., Bessason, B., Hårvik, L.: Prediction model for low frequency vibration from high speed railways on soft ground. J. Sound Vib. 193, 195-203 (1996)

12. Madshus, C., Kaynia, A.M.: High-speed railway lines on soft ground: dynamic behaviour at critical train speed. J. Sound Vib. 231, 689-701 (2000)

13. Metrikine, A.V., Vrouwenvelder, A.C.W.M.: Surface ground vibration due to a moving train in a tunnel: two-dimensional model. J. Sound Vib. 234, 43-66 (2000)

14. Nielsen, J.C.O., Oscarsson, J.: Simulation of dynamic train-track interaction with state dependent track properties. J. Sound Vib. 275, 515-532 (2004)

15. Paolucci, R., Maffeis, A., Scandella, L., Stupazzini, M., Vanini, M.: Numerical prediction of low-frequency ground vibrations induced by high-speed trains at Ledsgaard, Sweden. Soil Dyn. Earthquake Eng. 23, 425-433 (2003)

16. Picoux, B., Le Houéedec, D.: Diagnosis and prediction of vibration from railway trains. Soil Dyn. Earthquake Eng. 25, $905-$ $921(2005)$

17. Shamalta, M., Metrikine, A.V.: Analytical modelling of the dynamic response of an embedded railway track to a moving load. Arch. Appl. Mech. 73, 131-146 (2003)

18. Sheng, X., Jones, C.J.C., Thompson, D.J.: A comparison of a theoretical model for quasi-statically and dynamically induced environmental vibration from trains with measurements. J. Sound Vib. 267, 621-635 (2003)

19. Steenbergen, M.J.M.M., Metrikine, A.V.: The effect of the interface conditions on the dynamic response of a beam on a half-space to a moving load. Eur. J. Mech. A/Solids 26, 33-54 (2007)

20. Takemiya, H.: Simulation of track-ground vibrations due to a high-speed train: the case of X-2000 at Ledsgard. J. Sound Vib. 261, 503-526 (2003)

21. U.S. Department of Transportation: High-speed ground transportation noise and vibration impact assessment. Office of Railroad Development, report 293630-1 (1998)

22. Vostroukhov, A.V., Metrikine, A.V.: Periodically supported beam on a visco-elastic layer as a model for dynamic analysis of a high-speed railway track. Int. J. Solids Struct. 40, 5723-5752 (2003)

23. With, C.: Validation of two models for prediction of train induced ground vibrations. Lic. Thesis, Royal Institute of Technology (2005)

24. With, C., Bodare, A.: Prediction of train-induced vibrations inside buildings using transfer functions. Soil Dyn. Earthquake Eng. 27, 93-98 (2007) 